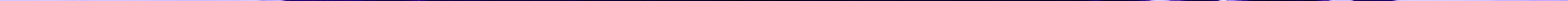




\title{
Adaptación, osadía e innovación, coordenadas del ecosistema educativo en la pandemia
}

\author{
Dr. José Luis López Aguirre
}

Profesor: que te ilusione hacer entender a los alumnos, en poco tiempo, lo que a ti te ha costado horas de estudio ver claro.

San José María Escrivá.

A la memoria de nuestra colega Leticia González †

E I presente cuarto número de nuestra Revista Panamericana de Comunicación sirva para conmemorar, en su acepción de homenaje más que de celebración, a los docentes y estudiantes que continúan enfrentando con resiliencia y creatividad los retos y exigencias que plantea la pandemia por la COVID-19. Asimismo, dedicamos este monográfico a los colegas que han partido, pero que sus enseñanzas perduran.

En este desafiante e incierto escenario que ha caracterizado el comienzo del segundo decenio del siglo XXI, el sector educativo ha tenido que reinventarse, como gratamente lo evidencian los diecisiete artículos provenientes de quince universidades hispanoamericanas que conforman la edición titulada Buenas prácticas docentes y de investigación en las carreras de Comunicación durante el confinamiento sanitario.

Especialmente el esfuerzo continuo de adaptación e innovación, avivado por la osadía de las autoras y autores de esta variopinta muestra de estrategias didácticas y pedagógicas, que están siendo modeladas por la apropiación de las nuevas tecnologías de la información, configuran el devenir del ecosistema panamericano de experiencias de enseñanza-aprendizaje.
Ha sido una fructífera experiencia responsabilizarme, en compañía de mi querido colega el Dr. José López Yepes, de la edición del presente número. Pero también un reto y al final un agradable acierto, porque el tema de nuestra convocatoria está siendo objeto de tratamiento en diversas revistas científicas y congresos internacionales. Ya en la convocatoria de este número afirmábamos que se buscaba seleccionar y compartir un conjunto de prácticas eficientes e innovadoras que docentes e investigadores iberoamericanos del campo de la Comunicación tuvieran que idear, diseñar, articular e implementar para continuar con sus labores docentes y de investigación frente a la problemática que plantea la contingencia sanitaria.

Con acierto nos adelantamos a varios llamados para publicar y presentar ponencias sobre esta coyuntural temática. Nuestra convocatoria logró reunir un interesante abanico de aportaciones de la comunidad científica. Y tras el loable trabajo de nuestro equipo de evaluadores, se seleccionaron y mejoraron nada menos que diecisiete artículos elaborados por profesores de tiempo completo y de asignatura procedentes de universidades de España (7), México (5), Estados Unidos (2), Uruguay, Perú y Bolivia. 
El contenido de estos trabajos delinea algunas coordenadas del desarrollo del ecosistema educativo en la pandemia. Las referencias apuntan hacia la innovación en las experiencias de enseñanza-aprendizaje (Campos Jiménez, Terrones Lizana, López Yepes, López Aguirre, Suárez Ramírez, Valenzuela Reyes y Flores Heymann), estudios de caso (Gago y otros y Vivas Moreno y Valhondo Crego), proyectos audiovisuales (Parentelli y Sanz de León y Montes Rodríguez), resultados de la colaboración interuniversitaria (Magrane y Garduño) y el rol docente (García).

En la sección de Miscelánea se presenta el informe de un caso de éxito redactado por Constantino, Fernández-Gómez y otros, la puesta en marcha de un grado online que comparte Feijoo-Fernández y un trabajo de fuentes de documentación sobre el tema que nos ocupa facilitado por A. López Yepes. Como advertirán se trata de una variada oferta de buenas prácticas docentes en las carreras de Comunicación realizadas durante el confinamiento sanitario que esperamos los anime a la lectura e interacción con nuestros autores.

El sector educativo no volverá a ser el mismo. Esta sacudida provocada por la pandemia no es momentánea, nos obliga a repensar constantemente nuestro quehacer docente; a navegar todos los días en aguas turbulentas (un mar en calma nunca hizo buenos marineros). $Y$ especialmente a reaprender (aprender de formas distintas a la que estamos acostumbrados) a trabajar codo a codo con nuestros alumnos, no importa si se trata de un curso presencial, en línea o híbrido. 